\title{
Assessing the impact of introduced cats on island biodiversity by combining dietary and movement analysis
}

\author{
S. Hervías ${ }^{1,3,4}$, S. Oppel ${ }^{2}$, F. M. Medina ${ }^{3,5}$, T. Pipa ${ }^{4}$, A. Díez ${ }^{4}$, J. A. Ramos ${ }^{6}$, R. Ruiz de Ybáñez \& \\ M. Nogales ${ }^{3}$ \\ 1 Animal Health Department, Faculty of Veterinary, Regional Campus of International Excellence 'Campus Mare Nostrum', University of Murcia, \\ Murcia, Spain \\ 2 Royal Society for the Protection of Birds (RSPB), London, UK \\ 3 Island Ecology and Evolution Research Group (IPNA-CSIC), La Laguna, Spain \\ 4 Portuguese Society for the Study of Birds (SPEA), Lisboa, Portugal \\ 5 Servicio de Medio Ambiente, Cabildo Insular de La Palma, La Palma, Spain \\ 6 Department of Life Sciences, Marine and Environmental Research Center (IMAR/CMA), University of Coimbra, Coimbra, Portugal
}

\section{Keywords}

feral cats; domestic cats; generalist

predator; GPS; home-range size; prey

availability; scat composition.

\section{Correspondence}

Sandra Parejo Hervías, Faculty of Veterinary,

University of Murcia, Animal Health

Department, Espinardo, Murcia 30100,

Spain. Tel: +34 868884 719; Fax:

+34868 884147

Email: shparejo@gmail.com

Editor: Virginia Hayssen

Received 18 April 2013; revised 8 August

2013; accepted 15 August 2013

doi:10.1111/jzo.12082

\begin{abstract}
Populations of feral (not owned by humans) and domestic cats Felis catus coexist in most inhabited islands, and they have similar impacts on native species. Feral cats are generally believed to vary their diet according to prey availability; however, no previous studies of diet have tested this hypothesis on insular ecosystems with a limited range of available prey. Because domestic cats kill prey independently of hunger, the spatial extent of their impact on wildlife will be influenced by home-range size. In this study, we combined dietary information with cat movements to assess the impacts of feral and domestic cats on island biodiversity. We quantified the diet of cats from scat samples collected across one year and tested whether diet varies by season. The abundance of main prey categories was also estimated to document seasonal variation in prey availability for cats. Finally, we tracked domestic cats by global positioning system units in all four seasons to examine whether home-range patterns varied seasonally. The diet of cats constituted three prey groups (rodents, birds and invertebrates), and the seasonal variation in consumption of each taxon matched the seasonal variation in prey availability, thus supporting the generalist behaviour of cats on oceanic islands. Roaming behaviour varied among individuals and across seasons, but could not be explained by availability of prey. Unconfined cats had larger homeranges than confined cats, but most domestic cats strayed $<1 \mathrm{~km}$ from home. Thus, confinement of domestic cats might reduce the spatial extent of cat impact on native prey populations on oceanic islands.
\end{abstract}

\section{Introduction}

Negative impacts of introduced cats Felis catus have been reported on islands worldwide (Medina et al., 2011), and cats have caused irreversible damage to populations of many native species (Fitzgerald \& Turner, 2000). To assess the impacts of cats on native biodiversity, it is important to understand where cats find their prey and what species they consume.

Cats feed on a wide variety of prey (Van Aarde, 1980) and hence are considered generalist predators, exploiting prey species according to their abundance (Fitzgerald \& Karl, 1979). Native species on oceanic islands are particularly vulnerable to cat predation because of their lack of antipredator behaviour. Conservation of island biodiversity therefore requires knowledge of whether cats prefer to consume native species that are easy to capture, or whether they consume species at random in proportion to their relative abundance.

Although the diet of introduced cats on islands has been extensively investigated (Bonnaud et al., 2011), we are not aware of a study of cat diet that simultaneously measured the availability of prey. Simultaneous monitoring of diet and prey abundance is important to assess the role of cats as generalist predators and thus their impact on native species.

The impact of cats on native biodiversity also depends on the spatial extent over which prey is encountered. This is a particular concern for domestic (owned and fed by humans) cat populations (van Heezik et al., 2010; Horn et al., 2011), which coexist with feral cats (not owned by humans) on most inhabited islands where cats have been introduced. Domestic cats frequently kill wild prey and can have impacts on the 
environment similar to feral cats (Loss, Will \& Marra, 2013). Although domestic cats generally receive supplementary food from humans, their urge to hunt and kill influences their home-range size (Barratt, 1997). Data on spatial movements might therefore be informative to identify which native species may be affected by domestic cats. Previous attempts at assessing cat impacts suggest that home-range size varies with sex, neuter status (whether a domestic cat has been neutered or not), and seasonal prey availability (Barratt, 1997; Edwards et al., 2001). However, most studies did not account for seasonal variation in home-range size or differences between individuals (Lilith, Calver \& Garkaklis, 2008). Because sterilization and confinement would offer management tools to reduce the impacts of domestic cats on native species, more information is required on how neuter and confinement status affect home-range size and thus the spatial extent of cat impacts on native wildlife.

In this study we combined information on diet - which species are consumed - with information on home-range sizewhere species are exposed to cat predation - to assess the potential impacts of cats on a remote oceanic island inhabited by humans. We quantified the diet composition of cats by analysing scat samples to identify different prey, and we estimated the abundance of prey to document seasonal variation in prey availability across one year. This allowed us to assess whether seasonal fluctuation in cat diet resembled seasonal prey availability and test whether cats consume prey taxa in proportion to their abundance. We expected that if cats were generalist predators differences in diet composition across seasons would correlate with availability of prey.

Because the impacts of cats on islands depend not only on their dietary preferences, but also on the area where prey is encountered, we tracked domestic cats with global positioning system (GPS) loggers and estimated their home-ranges in four seasons. We then investigated whether seasonal variation in home-range could be explained by seasonal variation in prey availability, or whether individual-level factors such as age, sex, neuter and confinement status had more influence on variation in a cat's home-range size. We hypothesized that the home-range would not vary with prey availability because the cats we tracked were fed by humans throughout the year. Instead, we expected large differences in roaming behaviour between sexes, neuter and confinement status. This analysis provides valuable information for the management of domestic cats on islands to reduce the impact of cats on populations of native species.

\section{Methods}

\section{Study site and resident cat population}

This study was carried out on Corvo (39 $40^{\prime} \mathrm{N}, 31^{\circ} 07^{\prime} \mathrm{W}$; Atlantic Ocean), a small oceanic island $\left(17 \mathrm{~km}^{2} ; 0-718 \mathrm{~m}\right.$ above sea level) that is primarily used for cattle grazing. The island is covered by pastures, one small village, some arable land, a few small fragments of forest and extensive rocky cliffs (Fig. 1). The weather is characterized by moderately hot and sunny summers, and frequent rain and strong wind in autumn

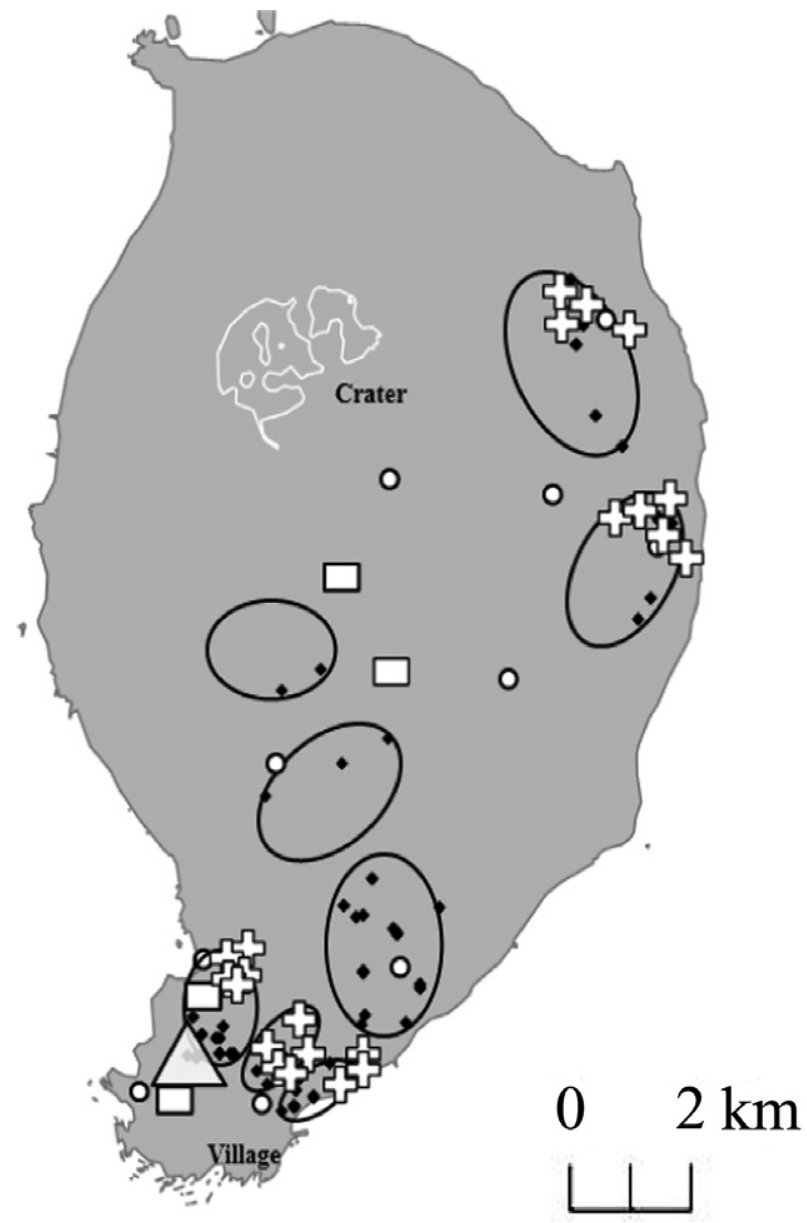

Figure 1 Spatial distribution of sampling areas (in white) to estimate the abundance of rodents (rectangle), landbirds (circles), Cory's shearwater Calonectris diomedea borealis nests (crosses) and invertebrates (triangle), and (in black) the eight areas (ellipses) surveyed to characterize the diet of cats Felis catus and the scat samples collected (squares) on Corvo Island.

and winter. Within this insular ecosystem, introduced cats function as top predator with two introduced mesopredator species: house mouse Mus domesticus and black rat Rattus rattus.

The cats inhabiting Corvo can be classified into three different types varying by the degree of human ownership and care: confined domestic or house cats, free-roaming domestic or stray cats (owned but not confined), and truly feral cats with no human owners and freely breeding in the wild (see Liberg et al., 2000 for details). On Corvo, confined cats were readily approachable by everyone and spent more time inside their houses, whereas unconfined cats were only handled by owners (Bradshaw et al., 1999). The cat population on Corvo has been estimated to consist of around 150-200 feral cats and 100-120 domestic cats (Oppel et al., 2012). Our study describes the diet of all cat types and the movements of 
confined and unconfined domestic cats, because it was not possible to recover GPS units from feral individuals.

\section{Diet characterization}

We characterized cat diet by collecting scat samples and identifying prey remains in those samples. A total of 146 scats were collected on eight areas that were surveyed weekly (from September 2010 to August 2011). Within each area, a survey consisted of a 1-km transect around pastures that are heavily used by cats on Corvo (Hervías et al., 2012; Oppel et al., 2012): near seabird colonies, near haylofts with suitable shelter and near rock walls (Fig. 1). Individual prey items were identified using reference material from our own collection. Dietary information is presented in terms of number of prey, percentage of prey items $(\% \mathrm{RF})$, frequency of occurrence $(\% \mathrm{~F})$ and biomass $(\% \mathrm{~B}$; Supporting Information Table S1). From these measures we calculated an index of relative importance (IRI) as $\% \mathrm{~F} *(\% \mathrm{RF}+\% \mathrm{~B})$ to rank prey according to its relative importance, in order to reduce possible bias in dietary description due to species size (Medina et al., 2010). Human and vegetable food was excluded.

\section{Prey availability}

We measured the relative abundance of four prominent prey taxa (rodents, landbirds, seabirds, invertebrates) in the main habitat type on the island (pastures) where all cat scat transects were located (Fig. 1). For rodents we surveyed areas at two different altitudes: two grids $<250 \mathrm{~m}$ and two grids $>250 \mathrm{~m}$. Because the abundance of invertebrate species can vary with the intensity of pasture management (Cardoso et al., 2009), we surveyed invertebrates within an area with a gradient from grazed to un-grazed grassland. For landbirds 10 randomly-selected locations were surveyed across the island.

The abundance of rodents was estimated using live-traps. Rodents were trapped for four consecutive nights every month from March 2010 to February 2011, except in July and December 2010. Traps were wired open and left un-baited between seasons to reduce trap-shyness (Hervías et al., 2012). We calculated an abundance index per season as the number of individuals captured per 100 trap nights for each rodent species.

For landbirds, five-minute point counts were conducted in September and December 2010 and March and June 2011 by the same observer during favourable weather within four hours after sunrise. Because the landbird community on Corvo is species-poor (seven species), we used the total number of all species, seen or heard, during a survey as an index of landbird abundance. Landbirds are more conspicuous during their breeding season and this behaviour increases both the likelihood of detection and predation by cats (Brown et al., 1998). To reduce confounding abundance with increasing detectability due to singing behaviour, we counted only birds that were detected by their contact or alarm calls in each season.

Among seabirds, we focused on Cory's shearwater Calonectris diomedea borealis because it is the most common species on Corvo, and probably the only seabird species acces- sible for cats. To quantify the seasonal availability of Cory's shearwaters, we monitored 169 known nests during the breeding season (from May to November 2011) (Hervías et al., 2013), and assumed that shearwater availability was zero in winter and spring when the birds are at sea. Because both chicks and adults may be killed by cats, each occupied burrow contained a potential prey item and we used the number of occupied nests as an index of seabird availability.

Invertebrate abundance was measured with 12 pitfall traps randomly distributed at least $100 \mathrm{~m}$ apart. Each trap $(80 \mathrm{~mm}$ in diameter and $140 \mathrm{~mm}$ deep) contained $150 \mathrm{ml}$ of Turquin's liquid (Turquin, 1973), and was in place for five consecutive nights in September and December 2010 and March and June 2011. Captured arthropods were identified to order level under a stereomicroscope (16x), and the total number of individuals in a survey was used as an index of abundance per season. Only species $>0.05 \mathrm{~g}$ were counted to avoid distortion of the index by superabundant small invertebrates.

\section{GPS tracking of cats}

A total of 21 cats were fitted with a GPS logger $(4.4 \times 2.7 \times$ $1.3 \mathrm{~cm}$ of size, iGot-U, Mobile Action Technology, New Taipei City, Taiwan) using an adjustable harness. All cats were weighed and classified according to age (reported by the owners: $<2$ years $=$ immature or $>2$ years $=$ adult), gender $($ by examination of external genitalia), neuter status (neutered or un-neutered) and confinement status (confined or unconfined). The GPS were programmed manually to attempt a location fix every 30 minutes. The tracking duration was determined by battery life, and whenever possible, cats were tracked simultaneously in July, August, September and December 2011, and January, April, July, September and November 2012. Date, time, latitude and longitude were downloaded for each successful location fix using the CatTraQ program (http://www.mr-lee.com). Location fixes of cat-borne GPS devices can be subject to positional error of up to $50 \mathrm{~m}$. To assess the magnitude of error and the size of a home-range solely derived from positional error, we also placed two to three stationary units on the roof-top and one indoors of a house in the village of Corvo in each season. These devices had plain view of the sky and thus experienced the most favourable satellite uplink conditions. The positional error estimated from stationary units is therefore a minimum error reflecting the location pattern to be expected from a cat on a roof top or confined to the house of its owner.

\section{Data analyses}

All cat scats collected in a given season were pooled to describe diet for each season (spring = March, April and May; summer = June, July and August; autumn = September, October and November; winter = December; January and February). Categorical data analyses were performed to compare the consumption of prey across seasons using the relative occurrence of each taxon in scats (\% of all scats in a season that contained a given taxon; Supporting Information Table S1). 
Table 1 Mean abundance (standard deviation) of house mouse Mus domesticus and black rat Rattus rattus individuals captured per 100 trap nights (ind/100TN), number of Cory's shearwater Calonectris diomedea borealis nests occupied and the maximum number of landbird and arthropod species counted during surveys carried out once per season, from March 2010 to November 2011 on Corvo Island

\begin{tabular}{lllll}
\hline & Autumn & Winter & Spring & Summer \\
\hline House mouse inds/100TN & $6.23(2.1)$ & $3.58(2.8)$ & $2.34(1.3)$ & $1.97(2.1)$ \\
Black rat inds/100TN & $0.81(0.9)$ & $0.01(0.2)$ & $0.29(0.9)$ & $0.39(0.6)$ \\
Shearwater_occupied nests $n$ & 55 & 0 & 92 & 138 \\
Landbirds_max $n$ & $205(90.4)$ & $293(60.4)$ & $355(80.9)$ & $268(60.4)$ \\
Artropods_max $n$ & $818(106.3)$ & $619(30.2)$ & $109(17.6)$ & $657(70.2)$ \\
\hline
\end{tabular}

See text for details on how prey abundance indices were measured.

We tested whether cats ate prey in proportion to its abundance using a Chi-square test. We first tested whether the seasonal consumption of a taxon was constant. We then explored whether seasonal consumption patterns were explained by seasonal availability for each taxon. For this test we used the relative occurrence per season as observed values, and the respective taxon's relative abundance in the environment in that season as expected value (Table 1). The null hypothesis assumed that cats consumed prey in proportion to its abundance, and we rejected the null hypothesis if $P<0.05$.

For each cat tracked with GPS, we estimated the homerange size in each season using kernel density estimation. We report home range size as the $95 \%$ kernel density and minimum convex polygon areas (100\% MCP) for comparison with other studies.

To determine whether home-range size varied in response to the availability of prey we used general linear mixed models to relate home-range size to explanatory variables, and included individual cats as a random effect to account for non-independence associated with sampling the same individuals over four seasons (Gillies et al., 2006). We used a multimodel inference approach to evaluate support for prey availability as explanatory variables, and first constructed a suite of biologically plausible candidate models investigating the influence of individual-level covariates on seasonal variation in home-range size. These individual-level covariates were then included in a suite of candidate models to examine which measure of prey availability would best explain seasonal variation in home-range size (Supporting Information).

All analyses were conducted using the packages 'adehabitat' (Calenge, 2006) and 'Ime4' in R 2.11.1 (Team, 2010). We present median home-range areas estimated from the most parsimonious model, and provide Akaike information criteria weights to quantify support for each model.

\section{Results}

\section{Diet}

A total of 278 prey items belonging to 17 different animal species were identified in the scats (Supporting Information Table S1). Mammals were the main prey both in number and biomass. House mice were the most important prey, followed by birds, black rats and invertebrates. All invertebrates belonged to the phylum Arthropoda.

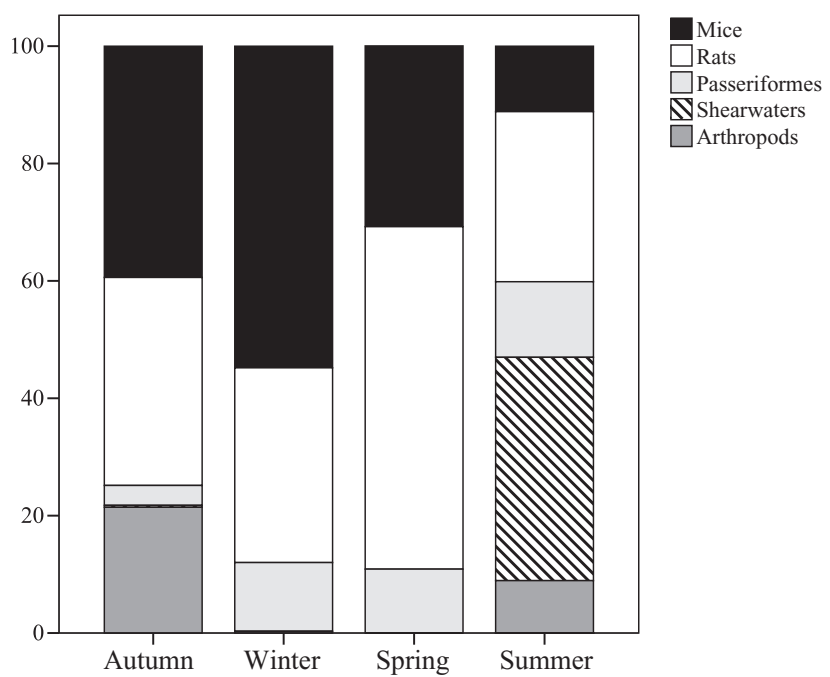

Figure 2 Seasonal variations in the percentage of the index of relative importance (IRI) in cat scats of the five main prey types preyed upon by cats Felis catus on Corvo Island. See text for details on how prey abundances were measured and how the $|R|$ was calculated.

Seasonal differences were observed in the IRI of each prey in diet (Supporting Information Table S1; Fig. 2). Mammals were consumed in higher proportion in spring and winter than in summer and autumn [house mice: $\chi^{2}=14.63$; degrees of freedom (d.f.) $=3 ; P=0.002$; black rats: $\chi^{2}=15.78$; d.f. $=3 ; P$ $=0.001]$. Seabirds were mostly preyed upon in summer $\left(\chi^{2}=\right.$ 17.61 ; d.f. $=3 ; P=0.001)$ when Cory's shearwater was included in the diet. Predation of landbirds decreased in summer and autumn $\left(\chi^{2}=33.17\right.$; d.f. $\left.=3 ; P<0.001\right)$ when the consumption of arthropods increased $\left(\chi^{2}=48.82\right.$; d.f. $=3 ; P<$ $0.001)$.

\section{Prey availability and occurrence in diet}

A total of 522 house mice and 17 black rats were captured mostly at low altitude, with the lowest abundances in winter and summer, respectively (Table 1). Passerines were the most frequently recorded landbirds and the maximum number was detected in spring. A total of 138 Cory's shearwater nests were 


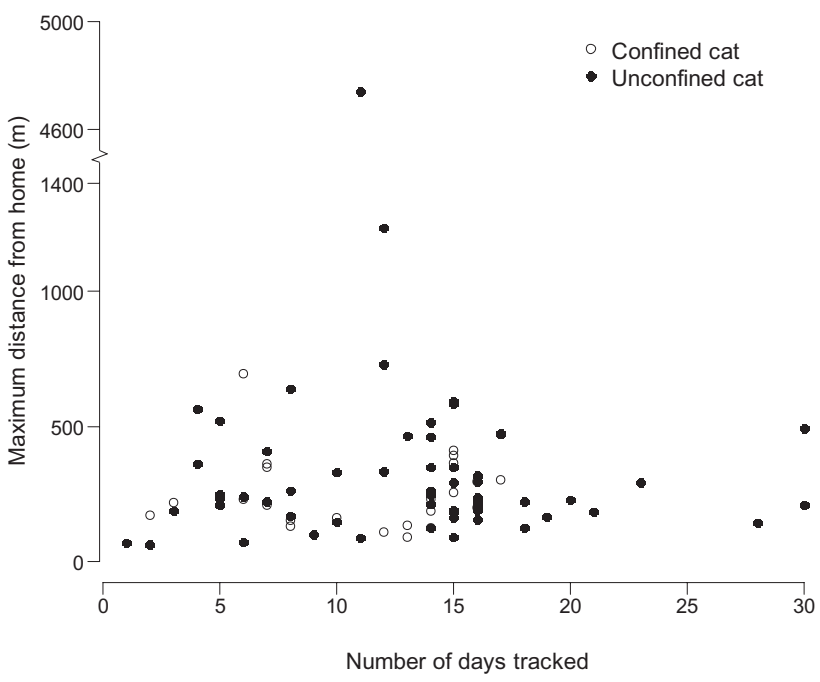

Figure 3 Maximum distances from home of confined and unconfined domestic cats Felis catus tracked with global positioning system on Corvo Island in relation to tracking duration.

occupied in summer. Invertebrates became very abundant in autumn, with the order Coleoptera being the most commonly detected.

Cats consumed prey in proportion to its availability, because seasonal changes in scat composition roughly matched seasonal changes in prey availability (house mice: $\chi^{2}$ $=0.12$, d.f. $=3, P=0.863$; black rats: $\chi^{2}=0.72$, d.f. $=3, P=$ 0.763; passerines: $\chi^{2}=0.07$, d.f. $=3, P=0.995$; Cory's shearwaters: $\chi^{2}=0.03$, d.f. $=1, P=0.851$; arthropods: $\chi^{2}=1.06$, d.f. $=3, P=0.785$ ).

\section{Cat movements and home-range size}

We tracked 21 individual cats ( 7 females and 14 males; 7 un-neutered and 14 neutered; 9 confined and 12 unconfined) ranging in weight from 0.5 to $8.0 \mathrm{~kg}$ and in age from 5 months to 11 years. During 70 deployments we obtained from 10 to 627 locations per deployment to estimate home-range size. An unconfined neutered male cat had the largest home-range in summer (73.9 ha). This large home-range was due to a single long trip around the entire eastern portion of the island in one of the seven nights over which the cat was tracked. During this long trip, the cat visited in sequence all known Cory's shearwater colonies in the area. Because no other equally long journey was recorded, this outstanding trip was excluded from further home-range analyses. Most cats never ventured further than $800 \mathrm{~m}$ from their home (Fig. 3).

Home-ranges were extremely variable among individuals and ranged from 0.5 ha in autumn to 20.3 ha in winter for two unconfined neutered male cats (Supporting Information Table S2; Fig. 4). Home-range sizes estimated from the stationary GPS loggers placed indoors (0.4-2.2 ha) and outdoors (0.4-0.5 ha) were similar to the home-ranges of confined cats in winter, but otherwise generally smaller.
Our initial exploration of individual-level factors indicated that home-range varied by age, neuter status and confinement status, but there was little support for sex and weight (Supporting Information Table S3). Besides differences among individuals, 'season' explained $10.0 \%$ of the variation and the model without 'season' received virtually no support. Models examining whether prey abundance could explain the seasonal variation in home-ranges received no support from the data (Table 2). The most parsimonious model indicated that homerange size increased slightly with age $[\beta=0.13 \pm 0.47$ standard error (SE)], and that unconfined cats had larger home-ranges than confined cats $(\beta=3.52 \pm 3.55 \mathrm{SE})$. The model also included an interaction between season and confinement status, indicating that seasonal variation in home-range size was more pronounced for unconfined than for confined cats. Although the most parsimonious model also included the neuter status, an equivalent model without neuter status received similar support (Supporting Information Table S3), because the estimated effect of neuter status was almost zero $(\beta=0.08 \pm 2.16 \mathrm{SE})$.

\section{Discussion}

\section{Are cats generalist predators on islands?}

According to general foraging theory, a generalist species consumes prey in proportion to prey availability, while a specialist prefers to consume a narrow spectrum of prey regardless of how abundant that prey is in the environment (Glasser, 1982). Most studies have suggested that cats consume prey in relation to its availability (Fitzgerald \& Karl, 1979), and our study supports this general theory because seasonal changes in cat diet matched seasonal fluctuations in prey abundance.

Black rats were important in the diet even when they reached the lowest abundance, and cats are known to prey heavily on rats on many islands (Bonnaud et al., 2011). Although rats are also known to prey on many seabird species (Jones et al., 2008), cats are the dominant predator of Cory's shearwaters on Corvo (Hervías et al., 2013). Cat predation on Cory's shearwater occurred mainly during the chick rearing stage, which coincided with low mouse availability. Therefore, cat predation on Cory's shearwaters is probably induced both by availability of defenceless chicks and a low abundance of house mice, which may lead to a partial shift in diet.

The generalist foraging behaviour of cats and their partial dependence on introduced rodents has important implications for the conservation of native biodiversity on islands. The eradication of introduced rodents would likely lead to even higher cat predation on native wildlife because cats would simply switch to alternative prey (Rayner et al., 2007). Therefore, the management of invasive vertebrates on islands needs to consider the trophic interactions between species because the removal of rodents on islands with apex predators such as cats may not lead to benefits for native biodiversity (Courchamp, Langlais \& Sugihara, 1999; Hervías et al., 2013). 

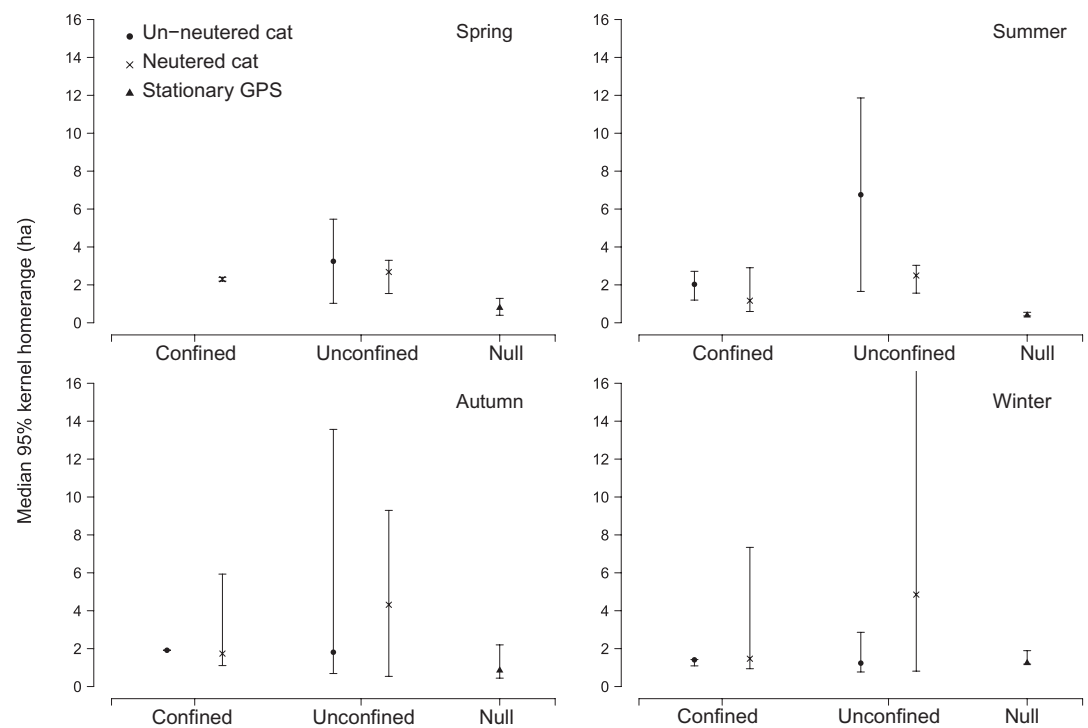

Figure 4 Median ( \pm ranges) 95\% kernel homerange size (ha) of domestic cats Felis catus tracked with global positioning system (GPS) in the four seasons across one year (from July 2011 to November 2012) on Corvo Island ( $n=69$ deployments). One unconfined, neutered male cat was excluded from this graph because its summer home-range was 74 ha due to a single long trip around most of the island. 'Null' homeranges are from stationary GPS units $(n=14)$ that were operational during the same period the cats were tracked, and reflect the home-range that is estimated from positional error alone.

Table 2 Model selection summary of nine candidate models explaining variation in home-range size ( $n=69$ deployments) of domestic cats Felis catus tracked on the island of Corvo once per season from July 2011 to November 2012

\begin{tabular}{|c|c|c|c|c|}
\hline Model & K & $\mathrm{AlCC}$ & $\Delta \mathrm{AIC} \chi$ & $\omega A I C \chi$ \\
\hline Age + neuter status + confinement $\times$ season & 12 & 402.42 & 0 & 1 \\
\hline Age + neuter status + confinement $\times$ rat $\times$ mice & 12 & 414.09 & 11.67 & 0 \\
\hline Age + neuter status + confinement $\times$ rat & 8 & 427.61 & 25.19 & 0 \\
\hline Age + neuter status + confinement $\times$ mice & 8 & 429.00 & 26.58 & 0 \\
\hline Age + neuter status + confinement $\times$ rat $\times$ bird & 12 & 433.81 & 31.39 & 0 \\
\hline Age + neuter status + confinement $\times$ bird & 8 & 442.33 & 39.91 & 0 \\
\hline Age + neuter status + confinement $\times$ invertebrates & 8 & 444.10 & 41.68 & 0 \\
\hline Age + neuter status + confinement $\times$ bird $\times$ mice & 12 & 453.06 & 50.64 & 0 \\
\hline Age + neuter status + confinement $\times$ invertebrates $\times$ mice & 12 & 463.75 & 61.33 & 0 \\
\hline
\end{tabular}

All models included age, neuter and confinement status and an offset for the number of days tracked. K, number of parameters of the model; AlC, Akaike Information Criteria.

\section{How important is native wildlife in the diet of cats on oceanic islands?}

Although introduced rodents were the dominant year-round component of cat diet on Corvo, and black rats contributed the largest proportion of biomass, cat consumption of Cory's shearwaters $(8.9 \%$ and $23.4 \%$ of frequency and biomass in summer and autumn) on Corvo was far higher than on the Canary Islands (3.2\% and 3.6\%; Nogales et al., 1988). Similarly, large-sized arthropods contributed more biomass to the diet on Corvo than in the Canary Islands (Nogales \& Medina, 2009). The reason for the strong reliance of cats on shearwaters and arthropods on Corvo in summer is presumably the absence of alternative prey such as rabbits or reptiles. This hypothesis is supported by the contribution of landbirds to cat diet on Corvo, which was similar to those on islands without reptiles $(12.9 \%$; Faulquier et al. 2009, 36\%; Fitzgerald, Karl \& Veitch, 1991).
We conclude that cat diet on oceanic islands reflects the entire spectrum of available prey. Introduced rodents or rabbits may reduce cat predation rate on native wildlife, but because cats are generalist predators, any vulnerable native prey species will likely suffer from cat predation. The presence of alternative prey such as rodents and rabbits is therefore unlikely to alleviate cat predation on native wildlife because the year-round availability of introduced prey species may boost cat populations and thus ultimately increase the absolute amount of cat predation on native wildlife. It is likely that seabird species smaller than Cory's shearwater formed a large part of the diet of cats on Corvo in the past (Monteiro, Ramos $\&$ Furness, 1996). As these seabird species were not found in cat scats in our study, cats likely exterminated accessible colonies of these species (Fitzgerald et al., 1991). Without the availability of introduced rodents as alternative prey, the feral cat population would not have survived the extermination of an important food source, highlighting the adverse effect 
of introduced rodents in supplementing predator populations on islands.

\section{How far do domestic cats range on an island?}

We found no evidence that seasonally varying abundance of prey taxa explained variation in the home-range size of domestic cats. Instead, home-ranges were extremely variable among individuals and seasons as has been found elsewhere (0.3-69.0 ha; Metsers, Seddon \& van Heezik, 2010, 0.521.8 ha; van Heezik et al., 2010). While confined cats that receive sufficient food from human owners may not need to adjust their roaming behaviour to prey availability, even the unconfined cats in our study did not display a consistent response to the availability of prey that we measured. Because cats appear to be generalist predators, the roaming behaviour may be controlled by factors other than food requirements, such as temperature, photoperiod, precipitation or territoriality (Goszczynski, Krauze \& Gryz, 2009).

Overall, we found high individual variation in home-range size, and all our covariate subgroups therefore had small sample sizes, rendering their mean size estimates less robust. We found a small positive effect of age on home-range size, possibly because young cats show reduced dispersal behaviour until they are 1-3 years old (Liberg, 1980). Confined cats had generally smaller home-ranges than unconfined cats, and tended to roam less far from their home (Fig. 3), therefore cat owners could be encouraged to confine the cat to the immediate vicinity of the house. If individual cats display consistent individual roaming behaviour, identifying and constraining the widest roaming cats may be easier to implement than other generally applicable cat constraint approaches (Calver et al., 2011). Another potential management option is to restrict cat ownership in human settlements that are too close to vulnerable native wildlife congregations such as seabird colonies. Our study shows that confined cats are less likely to roam very far, but that some unconfined cats can move $>10 \mathrm{~km}$ in a single night. On average, however, movements were within a $1-\mathrm{km}$ radius around the owner's house, and impacts on native wildlife are presumably greatest within this radius.

The tracking of cats with GPS loggers provided a great opportunity to assess the spatial impact of domestic cats on native wildlife. Although GPS loggers have many advantages over conventional very high-frequency transmitters (Cagnacci et al., 2010), positional errors occur because of inclement weather, steep topography, buildings or surrounding vegetation that limit communication with orbiting satellites (Börger, Dalziel \& Fryxell, 2008). We used stationary units to estimate the bias that would result from positional error alone, and found that location imprecision would yield home-range sizes between 0.4 (outdoor) and 2.1 ha (indoor). Thus, estimates of home-range size $<2$ ha may not be meaningful for domestic cats tracked with the GPS loggers we used.

In summary, our study shows that introduced cats on islands are generalist predators that can be expected to prey on both native and introduced wildlife. Because of the availability of introduced rodents, cat predation pressure on native species may be locally reduced, but rodents likely supplement cat populations and thus facilitate continuing cat predation of native wildlife. While only eradication of feral cats from islands will ensure conservation of native biodiversity, the confinement of domestic cats to owner's homes and policies that preclude cat ownership within a $1-\mathrm{km}$ radius around important native biodiversity aggregations may be useful to minimize the impact of domestic cats on threatened island biodiversity.

\section{Acknowledgments}

The project LIFE07 NAT/P/000649 'Safe Islands for Seabirds' made this work possible. We thank J. Benedicto, J. Katzenberger, J. Landschoff, S. Monforte, P. Domingos and cats' owners for help with fieldwork. We are grateful to Vítor Paiva and Pedro Geraldes for providing stimulating discussions on the design and analysis of results and for the GPS units. The project was funded by the IMAR, RSPB and SPEA. The authors declare that this study complied with the current laws of Portugal. The associate editor and two anonymous referees gave all kind of useful advices to improve the paper.

\section{References}

Barratt, D.G. (1997). Home range size, habitat utilisation and movement patterns of suburban and farm cats Felis catus. Ecography 20, 271-280.

Bonnaud, E., Medina, F.M., Vidal, E., Nogales, M., Tershy, B., Zavaleta, E., Donlan, C.J., Keitt, B., Le Corre, M. \& Horwath, S.V. (2011). The diet of feral cats on islands: a review and a call for more studies. Biol. Invasions 13, 581603.

Börger, L., Dalziel, B.D. \& Fryxell, J.M. (2008). Are there general mechanisms of animal home range behaviour? A review and prospects for future research. Ecol. Lett. 11, 637-650.

Bradshaw, J.W.S., Horsfield, G.F., Allen, J.A. \& Robinson, I.H. (1999). Feral cats: their role in the population dynamics of Felis catus. Appl. Anim. Behav. Sci. 65, 273-283.

Brown, K.P., Moller, H., Innes, J. \& Jansen, P. (1998). Identifying predators at nests of small birds in a New Zealand forest. Ibis (Lond. 1859) 140, 274-279.

Cagnacci, F., Boitani, L., Powell, R.A. \& Boyce, M.S. (2010). Animal ecology meets GPS-based radiotelemetry: a perfect storm of opportunities and challenges. Philos. Trans. $R$. Soc. B: Biol. Sci. 365, 2157-2162.

Calenge, C. (2006). The package "adehabitat" for the R software: A tool for the analysis of space and habitat use by animals. Ecol. Model. 197, 516-519.

Calver, M.C., Grayson, J., Lilith, M. \& Dickman, C.R. (2011). Applying the precautionary principle to the issue of impacts by pet cats on urban wildlife. Biol. Conserv. 144, 1895-1901. 
Cardoso, P., Aranda, S.C., Lobo, J.M., Dinis, F., Gaspar, C. \& Borges, P.A. (2009). A spatial scale assessment of habitat effects on arthropod communities of an oceanic island. Acta. Oecol. 35, 590-597.

Courchamp, F., Langlais, M. \& Sugihara, G. (1999). Cats protecting birds: modelling the mesopredator release effect. J. Anim. Ecol. 68, 282-292.

Edwards, G., De Preu, N., Shakeshaft, B., Crealy, I. \& Paltridge, R. (2001). Home range and movements of male feral cats (Felis catus) in a semiarid woodland environment in central Australia. Austral Ecol. 26, 93-101.

Faulquier, L., Fontaine, R., Vidal, E., Salamolard, M. \& Le Corre, M. (2009). Feral cats Felis catus Threaten the Endangered Endemic Barau's Petrel Pterodroma baraui at Reunion Island (Western Indian Ocean). Waterbirds 32, 330-336.

Fitzgerald, B.M. \& Karl, B. (1979). Foods of feral house cats (Felis catus L.) in forest of the Orongorongo Valley, Wellington. New Zeal. J. Ecol. 6, 107-126.

Fitzgerald, B.M. \& Turner, D.C. (2000). Hunting behaviour of domestic cats and their impact on prey populations, In The domestic cat: the biology of its behaviour: 151-175. Turner, D.C. \& Bateson, P. (Eds). Cambridge: Cambridge University Press.

Fitzgerald, B.M., Karl, B. \& Veitch, C. (1991). The diet of feral cats (Felis catus) on Raoul Island, Kermadec Group. New Zeal. J. Ecol. 15, 123-129.

Gillies, C.S., Hebblewhite, M., Nielsen, S.E., Krawchuk, M.A., Aldridge, C.L., Frair, J.L., Saher, D.J., Stevens, C.E. \& Jerde, C.L. (2006). Application of random effects to the study of resource selection by animals. J. Anim. Ecol. 75, 887-898.

Glasser, J.W. (1982). A theory of trophic strategies - the evolution of facultative specialists. Am. Nat. 119, 250-262.

Goszczynski, J., Krauze, D. \& Gryz, J. (2009). Activity and exploration range of house cats in rural areas of central Poland. Folia Zool. Brno 58, 363-371.

Hervías, S., Silva, C., Pipa, T., Oliveira, N., Henriques, A., Geraldes, P.L., Mealha, S., Diaz, E., Bravo, I., Oppel, S. \& Medina, F.M. (2012). Invasive mammal species on Corvo Island: is their eradication technically feasible? Airo 22, $12-28$.

Hervías, S., Henriques, A., Oliveira, N., Pipa, T., Cowen, H., Ramos, J., Nogales, M., Geraldes, P., Silva, C. \& de Ybáñez, R.R. (2013). Studying the effects of multiple invasive mammals on Cory's shearwater nest survival. Biol. Invasions 15, 143-155.

Horn, J.A., Mateus-Pinilla, N., Warner, R.E. \& Heske, E.J. (2011). Home range, habitat use, and activity patterns of free-roaming domestic cats. J. Wildl. Manage. 75, 11771185.

Jones, H.P., Tershy, B.R., Zavaleta, E.S., Croll, D.A., Keitt, B.S., Finkelstein, M.E. \& Howald, G.R. (2008). Severity of the effects of invasive rats on seabirds: a global review. Conserv. Biol. 22, 16-26.
Liberg, O. (1980). Spacing patterns in a population of rural free roaming domestic cats. Oikos 35, 336-349.

Liberg, O., Sandell, M., Pontier, D. \& Natoli, E. (2000). Density, spatial organisation and reproductive tactics in the domestic cat and other felids, In The Domestic Cat. The Biology of its Behaviour: 119-148. Turner, D.C. \& Bateson, P. (Eds). Cambridge: Cambridge University Press.

Lilith, M., Calver, M. \& Garkaklis, M. (2008). Roaming habits of pet cats on the suburban fringe in Perth, Western Australia: what size buffer zone is needed to protect wildlife in reserves? Aust. Zool. 34, 65-72.

Loss, S.R., Will, T. \& Marra, P.P. (2013). The impact of freeranging domestic cats on wildlife of the United States. Nat. Commun. 4, 1396.

Medina, F.M., Oliveira, P., Menezes, D., Teixeira, S., García, R. \& Nogales, M. (2010). Trophic habits of feral cats in the high mountain shrublands of the Macaronesian islands (NW Africa, Atlantic Ocean). Acta Theriol. (Warsz) 55, 241-250.

Medina, F.M., Bonnaud, E., Vidal, E., Tershy, B.R., Zavaleta, E.S., Josh Donlan, C., Keitt, B.S., Corre, M., Horwath, S.V. \& Nogales, M. (2011). A global review of the impacts of invasive cats on island endangered vertebrates. Global Change Biol. 17, 3503-3510.

Metsers, E.M., Seddon, P.J. \& van Heezik, Y.M. (2010). Cat-exclusion zones in rural and urban-fringe landscapes: how large would they have to be? Wildl. Res. $\mathbf{3 7}$, 47-56.

Monteiro, L.R., Ramos, J.A. \& Furness, R.W. (1996). Past and present status and conservation of the seabirds breeding in the Azores Archipelago. Biol. Conserv. 78, 319328.

Nogales, M. \& Medina, F.M. (2009). Trophic ecology of feral cats (Felis silvestris f. catus) in the main environments of an oceanic archipelago (Canary Islands): an updated approach. Mamm. Biol. 74, 169-181.

Nogales, M., Martín, A., Delgado, G. \& Emmerson, K. (1988). Food spectrum of the feral cat (Felis catus L., 1758) in the jumper woodland on El Hierro (Canary Islands). Bonn. Zool. Beitr. 39, 1-6.

Oppel, S., Hervías, S., Oliveira, N., Pipa, T., Cowen, H., Silva, C. \& Geraldes, P. (2012). Estimating feral cat density on Corvo Island, Azores, to assess the feasibility of feral cat eradication. Airo 22, 3-11.

Rayner, M.J., Hauber, M.E., Imber, M.J., Stamp, R.K. \& Clout, M.N. (2007). Spatial heterogeneity of mesopredator release within an oceanic island system. Proc. Natl Acad. Sci. U. S. A. 104, 20862-20865.

Team, R.D.C. (2010). R: A language and environment for statistical computing. Vienna, Austria: R Foundation for Statistical Computing.

Turquin, M. (1973). Une biocenose cavernicole originale pour le Bugey: le puits de Rappe. Commptes Rendus 96e Congresse Naturel Sociétès Savantes, Toulouse 1971. Sciences 3, 235-256. 
Van Aarde, R. (1980). The diet and feeding behaviour of feral cats, Felis catus at Marion Island. S. Afr. J. Wildl. Res. 10, 123-128.

van Heezik, Y., Smyth, A., Adams, A. \& Gordon, J. (2010).

Do domestic cats impose an unsustainable harvest on urban bird populations? Biol. Conserv. 143, 121-130.

\section{Supporting Information}

Additional Supporting Information may be found in the online version of this article at the publisher's web-site:

Supporting Information Table S1. Number of prey ( $n \mathrm{P})$, percentage of different prey items $(\% \mathrm{RF})$, frequency of occurrence $(\% \mathrm{~F})$, and of biomass $(\% \mathrm{~B})$ of food items found in cats' scats Felis catus, grouped into the four seasons, on the island of Corvo from September 2010 to August 2011. Supporting Information Table S2. Domestic cats Felis catus tracked with global positioning system (GPS) units once per season from July 2011 to November 2012 on Corvo Island, Azores. Home ranges were determined by minimum convex polygon areas (100\% MCP) and 95\% kernel density estimation (KE). Stationary GPS units were operational during the same period the cats were tracked, and reflect the home range that is estimated from positional error alone.

Supporting Information Table S3. Model selection summary of 16 candidate models explaining variation in home-range size ( $n=70$ deployments) of domestic cats Felis catus tracked on the island of Corvo once per season from July 2011 to November 2012. 